\title{
Zinc Supplementation Attenuates Cardiac Remodeling After Experimental Myocardial Infarction
}

\author{
Andrea F. Gonçalves ${ }^{a} \quad$ Bertha F. Polegato $^{a} \quad$ Ana Angélica Fernandes ${ }^{b}$ \\ Larissa Lumi Ishikawac Katashi Okoshia Silméia G. Z. Bazan ${ }^{a}$ Marcos F. Minicuccia \\ Paula S. Azevedo ${ }^{a}$ Maura R. Ikoma ${ }^{d}$ Marcimara Penitenti ${ }^{d}$ \\ Fernanda Chiuso-Minicuccia $^{\text {Sergio A. R Paiva }}{ }^{a}$ Leonardo A. M. Zornoffa \\ aSão Paulo State University (Unesp), Botucatu Medical School, Internal Medicine Department, Botucatu, \\ bSão Paulo State University (Unesp), Institute of Biosciences of Botucatu, Chemistry and Biochemistry \\ Department, Botucatu, cSão Paulo State University (Unesp), Institute of Biosciences of Botucatu, \\ Microbiology and Immunology Department, Botucatu, dFlow Citometry Laboratory, Amaral Carvalho \\ Fundation, Jaú, Brazil
}

\section{Key Words}

Coronary occlusion $\bullet$ Function $\bullet$ Hypertrophy $\bullet$ Chronic remodeling $\bullet$ Zinc $\bullet$ Treg cells

\begin{abstract}
Background/Aims: the objective of our study was to evaluate the effects of zinc supplementation on cardiac remodeling following acute myocardial infarction in rats. Methods: Animals were subdivided into 4 groups and observed for 3 months: 1) Sham Control; 2) Sham Zinc: Sham animals receiving zinc supplementation; 3) Infarction Control; 4) Infarction Zinc. After the followup period, we studied hypertrophy and ventricular geometry, functional alterations in vivo and in vitro, changes related to collagen, oxidative stress, and inflammation, assessed by echocardiogram, isolated heart study, western blot, flow cytometer, morphometry, and spectrophotometry. Results: Infarction induced a significant worsening of the functional variables. On the other hand, zinc attenuated both systolic and diastolic cardiac dysfunction induced by infarction. Considering the infarct size, there was no difference between the groups. Catalase and superoxide dismutase decreased in infarcted animals, and zinc increased its activity. We found higher expression of collagens I and III in infarcted animals, but there was no effect of zinc supplementation. Likewise, infarcted animals had higher levels of IL-10, but without zinc interference. Nrf-2 values were not different among the groups. Infarction increased the amount of Treg cells in the spleen as well as the amount of total lymphocytes. Zinc increased the amount of CD4+ in infarcted animals, but we did not observe effects in
\end{abstract}


relation to Treg cells. Conclusion: zinc attenuates cardiac remodeling after infarction in rats; this effect is associated with modulation of antioxidant enzymes, but without the involvement of collagens I and III, Nrf-2, IL-10, and Treg cells.

\section{Introduction}

The process of cardiac remodeling after myocardial infarction is associated with a poor prognosis. In the acute phase, remodeling favors the formation of the aneurysm and predisposes the infarcted heart to ventricular rupture. Chronically, it is associated with a higher prevalence of malignant arrhythmias and ventricular dysfunction, as the noninfarcted region undergoes genetic, structural, and biochemical changes that will result in deterioration of the heart's functional capacity and death [1-5]. Therefore, strategies that attenuate remodeling result in improved postinfarction prognosis.

Recently, the role of zinc as a modulator of the cardiac remodeling process has been the object of interest of several studies [6-16]. Among the mechanisms suggested for the influence of zinc on cardiac remodeling, matrix metalloproteinases activity, increased oxidative stress, and inflammatory process seem to play a critical role.

An important issue is that the role of zinc supplementation on cardiac remodeling after myocardial infarction remains unknown. Therefore, the objective of our study was to evaluate the effects of zinc supplementation following acute myocardial infarction in rats by studying some of the main mechanisms involved in the cardiac remodeling process: hypertrophy and ventricular geometry, functional alterations in vivo and in vitro, changes related to collagen, oxidative stress, and inflammation.

\section{Materials and Methods}

This research protocol was approved by the Animal Ethics Committee of Botucatu Medical School, and it was performed in accordance with the National Institute of Health's Guide for the Care and Use of Laboratory Animals.

\section{Animals and Groups}

Male Wistar rats, weighing 200-250 g, were subjected to experimental myocardial infarction, according to the method described previously $[17,18]$ or a simulated surgery (without coronary artery occlusion).

The animals were housed in cages with 2 or 3 animals, with free access to water and feed. The temperature was maintained at $22 \pm 2^{\circ} \mathrm{C}$, and the humidity was controlled. Light cycles (light/dark) were 12 hours. The animals were weighed once a week throughout the experimental period.

We selected only animals with an infarct size greater than $35 \%$ as assessed by histologic analysis, because we considered that animals with small infarct size do not undergo cardiac remodeling [19].

After 3 to 5 days of performing the surgical procedure of infarction induction, an initial echocardiographic study was performed to evaluate systolic and diastolic areas and fraction of area variation in all animals, in addition to the measurement of infarct size in animals induced by occlusion of the coronary artery, to guarantee homogeneity between the groups (data not shown).

After the initial echocardiographic study, the animals were again subdividedinto 4 experimental groups and observed for 3 months: 1) Sham Control (SC): Sham animals that received intraperitoneal saline solution on alternate days; 2) Sham Zinc (SZ): Sham animals receiving zinc supplementation (zinc sulfate, $5 \mathrm{mg} / \mathrm{kg}$ ) intraperitoneally on alternate days; 3) Infarction Control (IC): Infarcted animals receiving intraperitoneal saline solution on alternate days; 4) Infarction Zinc (IZ): Infarcted animals receiving zinc supplementation (zinc sulfate, $5 \mathrm{mg} / \mathrm{kg}$ ) intraperitoneally on alternate days. The zinc dose used in our study was based on a previous study, which showed beneficial effects of this dose for preventing diabetic heart disease [20]. 


\section{Cellular Physiology Cell Physiol Biochem 2018;50:353-362

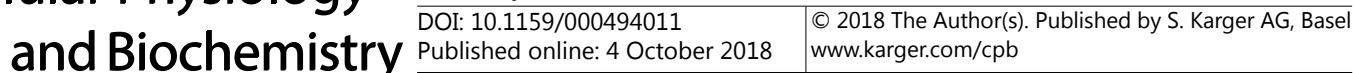 \\ \begin{tabular}{l|l} 
Published onlIne: 40 October 2018 www.karger.com/cpb \\
\hline Gonçalves et al: Zinc and Remodeling After Infarction
\end{tabular}}

\section{Echocardiographic analysis}

After 3 months, all the rats were weighed and evaluated by a transthoracic echocardiographic examination (General Electric Medical Systems, Vivid S6, Tirat Carmel, Israel). The following structural variables were measured: left atrium diameter, left ventricle (LV) diameter, diastolic and systolic dimensions, and LV diastolic posterior wall thickness. Systolic function was assessed based on the fractional area change (FAC), Tei index, and posterior wall shortening velocity (PWSV). The E/E' ratio and LA diameter were used as a variable of $\mathrm{LV}$ diastolic function [21].

\section{Isolated heart study: Langendorff preparation}

After 3 months of exposure, six animals from each group were anesthetized with thiopental $(80 \mathrm{mg} / \mathrm{kg}$, IP) and received unfractionated heparin (2, 000 IU, IP). After sternotomy, the rats were artificially ventilated, and the ascending aorta was dissected and cannulated. Retrograde perfusion was initiated with a modified Krebs-Henseleit solution, constantly gassed with a mixture of $95 \% \mathrm{O}_{2}$ and $5 \% \mathrm{CO}_{2}$, and a perfusion pressure of $75 \mathrm{mmHg}$ [22]. The heart was removed and transferred to an isolated heart perfusion apparatus (size 3, type 830, Hugo Sachs Elektronik - March-Hugstetten, Germany). A balloon was inserted in the LV cavity, and the volume inside the balloon was modified to obtain a diastolic pressure of zero at $25 \mathrm{mmHg}$. We registered the diastolic and systolic pressures, the maximum LV pressure decrease rate $(-\mathrm{dP} / \mathrm{dt})$ and the maximum $\mathrm{LV}$ pressure development rate $(+\mathrm{dP} / \mathrm{dt})$. Systolic function was evaluated by systolic pressure and $+\mathrm{dP} / \mathrm{dt}$, and diastolic function by $-\mathrm{dP} / \mathrm{dt}$. The hearts that were subjected to the isolated heart study were not utilized for any other analysis because retrograde perfusion can interfere with subsequent biochemical analysis.

\section{Morphometric analysis}

On completion of the echocardiographic study, the right and left ventricles (including the interventricular septum) were dissected, separated, and weighed. The lengths of the infarcted and the viable muscle for both the endocardial and epicardial circumferences were determined by planimetry. Infarct size was calculated by dividing the endocardial and epicardial circumferences of the infarcted area by the total epicardial and endocardial ventricular circumferences. The measurements were performed on ventricular sections (5-6 mm from the apex) under the assumption that the left mid-ventricular slice showed a close linear relationship with the sum of the area measurements from all the heart sections [23, 24].

\section{Antioxidant enzyme analysis}

LV samples $(100 \mathrm{mg})$ were homogenized in $5 \mathrm{ml}$ of $0.1 \mathrm{M}$ cold sodium phosphate buffer, $\mathrm{pH}$ 7.4, containing $1 \mathrm{mM}$ ethylenediaminetetraacetic acid. Tissue homogenates were prepared, and total protein concentration, glutathione peroxidase, superoxide dismutase (SOD), and catalase were assessed as previously specified [25]. All reagents were from Sigma (St. Louis, MO, USA).

Western blot analysis for Nrf-2, IL-10, and type I and III collagen

Samples of the LV were homogenized in RIPA buffer and diluted in Laemmli buffer to detect type I collagen (rabbit polyclonal IgG, sc8784R; Santa Cruz Biotechnology, Inc., Dallas, TX, USA) and type III collagen (mouse monoclonal IgG1, ab6310; Abcam, Inc., Cambridge, UK). Nuclear protein extraction from the LV was performed with the NE-PER Nuclear Extraction Reagents kit (Pierce Biotechnology, Rockford, IL, USA). Nuclear extracts were used to detect Nrf-2 (C-20, rabbit polyclonal IgG, sc722; Santa Cruz Biotechnology, Inc.). Secondary antibodies were used according to the manufacturer's recommendations, and GAPDH (GAPDH [6C5], mouse monoclonal IgG1, sc32233, Santa Cruz Biotechnology, Inc.) was used for normalization [26].

\section{Determination of regulatory $T$ cells (Treg) in the spleen}

The spleen was macerated with $1 \mathrm{ml}$ of incomplete RPMI medium, and this cell suspension was placed in a $15 \mathrm{ml}$ Falcon tube and the volume filled with incomplete RPMI medium (with gentamicin) to $7 \mathrm{ml}$ and then centrifuged at $300 \mathrm{~g}$, for 10 minutes, at $4^{\circ} \mathrm{C}$. The supernatant was discarded, and the red cells were lysed by resuspending the spleen pellet in $5 \mathrm{ml}$ of lysis buffer and incubated for 5 minutes at room temperature. Volume was completed with incomplete RPMI medium up to $15 \mathrm{ml}$ and centrifuged again at 
$300 \mathrm{~g}$, for 10 minutes, at $4^{\circ} \mathrm{C}$. The supernatant was discarded, and the cells resuspended in $1 \mathrm{ml}$ of complete RPMI medium (10\% FBS and 1\% L-glutamine). The number of cells was counted, with Turk dye.

CD4 and CD25 were labeled in a tube for light-protected cytometry (laminated paper). A total of 2.5 x $10^{6}$ cells were used in a total volume of $100 \mu \mathrm{l}+0.5 \mu \mathrm{g}(1 \mu \mathrm{l})$ CD4-FITC antibody $+0.25 \mu \mathrm{g}(1.3 \mu \mathrm{l})$ CD25APC antibody, incubated for 20 minutes at room temperature. For the isotype control, $75 \mu \mathrm{l}$ of cells $(2.5$ $\times 10^{6}$ cells $)+20 \mu \mathrm{l}(1 \mu \mathrm{g})$ anti-FITC $+5 \mu \mathrm{l}(0.5 \mu \mathrm{g})$ anti-APC were used. After labeling, $1 \mathrm{ml}$ of AutoMacs Running Buffer - Miltenyi Biotec buffer was centrifuged at $450 \mathrm{~g}$, for 10 minutes, at $4^{\circ} \mathrm{C}$. The supernatant was discarded and then labeled with Foxp3.

For labeling Foxp3, the pellet was resuspended, and $1 \mathrm{ml}$ of permeabilization/fixation buffer was added and then incubated at $4^{\circ} \mathrm{C}$ in the dark. After washing and centrifugation steps, $1 \mu \mathrm{l}(0.2 \mu \mathrm{g})$ of antiFoxp3-PE antibody was added. For the isotype control, $95 \mu \mathrm{l}$ permeabilization buffer $+5 \mu \mathrm{l}$ anti-PE was used. Incubation was performed in the dark. After washing and further centrifugation, the samples were read on a flow cytometer.

\section{Zinc dosage}

The blood of animals was collected and centrifuged at 3, $000 \mathrm{rpm}$ for 20 minutes at $4^{\circ} \mathrm{C}$, and the serum stored at $-80^{\circ} \mathrm{C}$. Subsequently, in a small fraction of the serum, the zinc dosage was made by atomic absorption spectrophotometry.

\section{Statistical analysis}

The data are represented as mean and standard deviation. Variables with non-normal distributions were normalized before comparisons. A two-way ANOVA test complemented by the Holm-Sidak test was used to compare the groups. For mortality comparison, we used the chi-square test. Data analysis was performed with SigmaStat for Windows v2.03 (SPSS, Inc., Chicago, IL, USA). The significance level was 5\%.

Table 1. Echocardiographic Data. SC=sham animals that received standard diet; SZ=sham animals that received diet with zinc supplementation; IC= infarcted animals that received standard diet; IZ= infarcted animals that received diet with zinc supplementation. LVDD: left ventricular diastolic diameter; LVSD: left ventricular systolic diameter; LVWT: posterior wall shortening velocity; FAC: fractional area change; SA: systolic area; DA: diastolic area. Data are expressed as the mean \pm standard error of the mean. $n=$ number of rats. $p(I)=p$ value of the $I$ effect; $p(V Z)=p$ value of the zinc effect; $p(I x Z)=p$ value of their interaction

\begin{tabular}{cccccccc}
\hline Variables & SC $(\mathrm{n}=15)$ & $\mathrm{SZ}(\mathrm{n}=15)$ & $\mathrm{IC}(\mathrm{n}=23)$ & $\mathrm{IZ}(\mathrm{n}=24)$ & $\mathrm{p}(\mathrm{I})$ & $\mathrm{p}(\mathrm{Z})$ & $\mathrm{p}(\mathrm{IxZ})$ \\
\hline LVDD (mm) & $7.5 \pm 0.2$ & $7.0 \pm 0.3$ & $9.4 \pm 0.2$ & $9.0 \pm 0.2$ & $<0.001$ & 0.079 & 0.874 \\
LVSD (mm) & $3.7 \pm 0.4$ & $3.1 \pm 0.4$ & $6.7 \pm 0.2$ & $6.2 \pm 0.2$ & $<0.001$ & 0.159 & 0.925 \\
LA (mm) & $5.5 \pm 0.1$ & $4.9 \pm 0.1$ & $6.2 \pm 0.1$ & $5.7 \pm 0.1$ & $<0.001$ & 0.028 & 0.524 \\
FAC (\%) & $57.8 \pm 12.9$ & $73.8 \pm 12.8$ & $24.2 \pm 8.9$ & $43.9 \pm 8.8$ & 0.003 & 0.091 & 0.899 \\
Tei index & $0.63 \pm 0.06$ & $0.45 \pm 0.07$ & $0.94 \pm 0.04$ & $0.82 \pm 0.04$ & $<0.001$ & 0.011 & 0.599 \\
LVWT (mm/s) & $55.6 \pm 2.5$ & $64.0 \pm 2.4$ & $36.1 \pm 1.5$ & $39.2 \pm 1.6$ & $<0.001$ & 0.010 & 0.245 \\
E/E' & $13.2 \pm 1.0$ & $11.9 \pm 1.1$ & $17.6 \pm 0.7$ & $15.5 \pm 0.7$ & $<0.001$ & 0.050 & 0.598 \\
SA (mm 2$)$ & $22.6 \pm 3.7$ & $11.2 \pm 3.6$ & $50.1 \pm 2.6$ & $44.0 \pm 2.6$ & $<0.001$ & 0.007 & 0.401 \\
DA (mm $\left.{ }^{2}\right)$ & $50.8 \pm 4.7$ & $40.1 \pm 4.6$ & $79.4 \pm 3.2$ & $73.9 \pm 3.2$ & $<0.001$ & 0.051 & 0.430
\end{tabular}




\section{Cellular Physiology Cell Physiol Biochem 2018;50:353-362

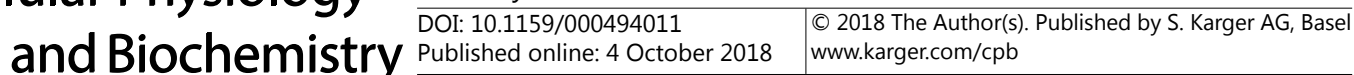 \\ Gonçalves et al:: Zinc and Remodeling After Infarction}

\section{Results}

After 48 hours of surgery, the mortality of infarcted animals was $27.7 \%$, with 125 surviving animals. In the noninfarcted group, all animals survived. During the follow-up period, 7 animals from the IC group and 6 animals from the IZ group died ( $p>0.05)$. As previously mentioned, we used only animals with infarctions greater than $35 \%$, thus totaling the number of animals indicated in the tables.

Echocardiogram results are shown in Table 1. As expected, infarction induced a significant worsening of the functional variables. On the other hand, zinc attenuated both systolic and diastolic cardiac dysfunction induced by infarction, assessed by Tei index, LVWT, LA diameter, and E/E' ratio.

In the study of the isolated heart, we found alterations in infarcted animals, with a decrease in the positive (SC $(\mathrm{n}=8)=2725 \pm 222 \mathrm{mmHg} / \mathrm{s}, \mathrm{SZ}(\mathrm{n}=8)=2850 \pm 232 \mathrm{mmHg} / \mathrm{s}$, IC $(\mathrm{n}=7)=1350 \pm 253 \mathrm{mmHg} / \mathrm{s}, \quad$ IZ $(\mathrm{n}=7)=1450 \pm 222 \mathrm{mmHg} ; \mathrm{p}(\mathrm{i})<0.001, p(z)=0.541$, $\mathrm{p}(\mathrm{iz})=0.542)$ and negative (SC $(\mathrm{n}=8)=1675 \pm 131 \mathrm{mmHg} / \mathrm{s}, \mathrm{SZ}(\mathrm{n}=8)=1875 \pm 141 \mathrm{mmHg} / \mathrm{s}$, IC $(\mathrm{n}=7)=875 \pm 155 \mathrm{mmHg} / \mathrm{s}, \mathrm{IZ}(\mathrm{n}=7)=975 \pm 131 \mathrm{mmHg} ; \mathrm{p}(\mathrm{i})<0.001, \mathrm{p}(\mathrm{z})=0.555, \mathrm{p}(\mathrm{iz})=0.880)$ derivatives as well as in the systolic pressure (SC (n=8)=163 $\pm 7.4 \mathrm{mmHg}$, SZ $\mathrm{n}=8)=153 \pm 7.2$ $\mathrm{mmHg}$, IC $(\mathrm{n}=7)=91 \pm 8.1 \mathrm{mmHg}, \quad$ IZ $\quad(n=7)=93 \pm 8.9 \mathrm{mmHg} ; \mathrm{p}(\mathrm{i})<0.001, p(z)=0.660$, $\mathrm{p}(\mathrm{iz})=0.705)$, but without the influence of zinc .

Considering the infarct size, there was no difference between the groups (IC $=42.6 \% \pm$ $6.5, \mathrm{IZ}=40.6 \% \pm 5.3 ; \mathrm{p}=0.691$ ).

The activity of enzymes related to oxidative stress are presented in Table 2. Catalase decreased in infarcted animals, and zinc increased its activity. Considering the enzyme SOD, the infarcted animals that received zinc supplementation had lower SOD activity than the infarcted control. Glutathione peroxidase decreased in infarcted animals, and zinc increased its activity.

Table 3 shows the protein expression levels. We found higher expression of collagens I and III in infarcted animals, but there was no effect of zinc supplementation. Likewise, infarcted animals had higher levels of IL-10, but without zinc interference. Nrf2 values were not different among the groups.

The leucocyte results are shown in Table 4. Infarction increased the amount of Treg cells

Table 2. Cardiac Oxidative Stress Enzyme Activity. SC=sham animals that received standard diet; $\mathrm{SZ}=$ sham animals that received diet with zinc supplementation; IC= infarcted animals that received standard diet; IZ= infarcted animals that received diet with zinc supplementation. CAT: catalase; SOD: superoxide dismutase; GSH-Px: glutathione peroxidase

\begin{tabular}{cccccccc}
\hline Variables & SC $(\mathrm{n}=10)$ & SZ $(\mathrm{n}=10)$ & $\mathrm{IC}(\mathrm{n}=10)$ & $\mathrm{IZ}(\mathrm{n}=10)$ & $\mathrm{p}(\mathrm{I})$ & $\mathrm{p}(\mathrm{Z})$ & $\mathrm{p}(\mathrm{IxZ})$ \\
\hline CAT & $75.1 \pm 6.76$ & $82.5 \pm 8.2$ & $57.8 \pm 6.76$ & $68.9 \pm 6.76$ & 0.045 & 0.213 & 0.798 \\
$(\mu \mathrm{mol} / \mathrm{g})$ & & & & & & & \\
SOD & & & & & & & \\
$(\mathrm{nmol} / \mathrm{mg})$ & $9.55 \pm 0.88$ & $8.15 \pm 1.08$ & $15.4 \pm 0.88$ & $11.2 \pm 0.88$ & $<0.001$ & 0.008 & 0.149 \\
GSH-Px $(\mathrm{nmol} / \mathrm{mg})$ & $34.4 \pm 2.45$ & $35.7 \pm 3$ & $30.3 \pm 2.45$ & $32.9 \pm 2.45$ & 0.200 & 0.466 & 0.806
\end{tabular}

Table 3. Cardiac Protein Expression. $\mathrm{SC}=$ sham animals that received standard diet; $\mathrm{SZ}=$ sham animals that received diet with zinc supplementation; IC= infarcted animals that received standard diet; $\mathrm{IZ}=$ infarcted animals that received diet with zinc supplementation. Nrf-2: nuclear factor erythroid 2-related factor 2; Col I: type I collagen; Col III: type III collagen; IL-10: interleucin $10 .{ }^{*} \mathrm{p}<0.05 \mathrm{vs}$. SC, IC and IZ

\begin{tabular}{cccccccc}
\hline Variables & $\mathrm{SC}(\mathrm{n}=8)$ & $\mathrm{SZ}(\mathrm{n}=8)$ & $\mathrm{IC}(\mathrm{n}=8)$ & $\mathrm{IZ}(\mathrm{n}=8)$ & $\mathrm{p}(\mathrm{I})$ & $\mathrm{p}(\mathrm{Z})$ & $\mathrm{p}(\mathrm{IxZ})$ \\
\hline Nrf-2 & $0.84 \pm 0.14$ & $1.06 \pm 0.13$ & $1.05 \pm 0,14$ & $1.07 \pm 0.14$ & 0.466 & 0.391 & 0.465 \\
Col I & $0.21 \pm 0.05$ & $0.27 \pm 0.04$ & $0.32 \pm 0.03$ & $0.42 \pm 0.04$ & 0.023 & 0.133 & 0.675 \\
Col III & $1.11 \pm 0.18$ & $0.79 \pm 0.20$ & $1.18 \pm 0.15$ & $1.45 \pm 0.16$ & 0.042 & 0.841 & 0.091 \\
IL-10 & $1.32 \pm 0.08$ & $1.39 \pm 0.09$ & $1.69 \pm 0.08$ & $1.53 \pm 0.07$ & 0.003 & 0.606 & 0.148
\end{tabular}


in the spleen as well as the amount of total lymphocytes. Zinc increased the amount of $\mathrm{CD} 4+$ in infarcted animals, but we did not observe effects of supplementation relation to Treg cells.

As expected, the zinc levels were higher in the supplemented animals $(\mathrm{SC}=99.1 \pm 4.29 \mu \mathrm{g} / \mathrm{dL}$; $\mathrm{SZ}=103 \pm 3.70 \quad \mu \mathrm{g} / \mathrm{dL} ;$ $\mathrm{IC}=100 \pm 4.29 \quad \mu \mathrm{g} / \mathrm{dL}$; $\mathrm{IZ}=114 \pm 4.29 \mu \mathrm{g} / \mathrm{dL} ; \mathrm{p}(\mathrm{I})=0.145 ; \mathrm{p}(\mathrm{Z})=0.034 ; \mathrm{p}(\mathrm{IXZ})=0.21)$.
Table 4. Leukocyte Count in the Spleen. SC=sham animals that received standard diet; $\mathrm{SZ}=$ sham animals that received diet with zinc supplementation; IC= infarcted animals that received standard diet; $\mathrm{IZ}=$ infarcted animals that received diet with zinc supplementation. CD4+CD25+Foxp3: Treg cells. ${ }^{*} \mathrm{p}<0.05$ vs. IC

\begin{tabular}{|c|c|c|c|c|c|c|c|}
\hline Variables & SC $(n=10)$ & $S Z(n=10)$ & IC $(n=10)$ & IZ (n=10) & $\mathrm{p}(\mathrm{I})$ & $\mathrm{p}(\mathrm{Z})$ & $\mathrm{p}(\mathrm{IxZ})$ \\
\hline Lymphocytes & $\begin{array}{c}87015 \pm \\
3033\end{array}$ & $\begin{array}{c}84506 \pm \\
8735\end{array}$ & $\begin{array}{c}88673 \pm \\
1365\end{array}$ & $\begin{array}{c}89777 \pm \\
1222\end{array}$ & 0.026 & 0.640 & 0.233 \\
\hline CD4+ & $\begin{array}{c}24614 \pm \\
3146\end{array}$ & $\begin{array}{c}22937 \pm \\
5039\end{array}$ & $\begin{array}{c}22865 \pm \\
3533\end{array}$ & $\begin{array}{c}26312 \pm \\
2793^{*}\end{array}$ & 0.495 & 0.458 & 0.036 \\
\hline CD4+CD25+Foxp3 & $878 \pm 314$ & $842 \pm 258$ & $1071 \pm 333$ & $1136 \pm 270$ & 0.013 & 0.877 & 0.590 \\
\hline
\end{tabular}

\section{Discussion}

The objective of this work was to evaluate the effects of zinc supplementation on cardiac remodeling after myocardial infarction. From the data presented, it can be suggested that variables associated with the remodeling process were attenuated by zinc supplementation.

The role of zinc as a modulator of cardiac changes has been prominent in recent years. Thus, previous studies have examined the cardiac effects of zinc on different clinical scanarios. For instance, a study showed an improvement in the LV relaxation by zinc in prediabetic animals, through the action of this mineral in the proteins linked to calcium transit, resulting in a lower intracellular calcium load [27]. In a study with zinc administration associated with acetylsalicylic acid (ASA) before the ischemic injury by isoproterenol in animals, an improvement in cardiac contractility and lower infiltration of inflammatory cells was observed compared with the group that was previously treated with ASA alone, showing beneficial effects of zinc supplementation in acute myocardial infarction, probably due to the induction of antioxidant enzymes and the anti-inflammatory cytokine TGF- $\beta 1$ [28]. In humans, serum zinc level was decreased in patients with heart failure and independently predicted clinical status and LV diastolic function [15]. However, the effects of zinc supplementation after infarction were unknown,

The most important result of our study was that zinc supplementation attenuated MIinduced LV remodeling. As expected, the infarction resulted in increased diastolic and systolic diameters of the LV. It should be emphasized that although the remodeling is an extremely complex event, after the infarction this process is clinically recognized by an increase in the LV cavity. In addition, a well-accepted concept is that the remodeling process is usually associated with deterioration of ventricular function [2-5]. Therefore, our study suggests that zinc administration attenuated infarct-induced ventricular remodeling, associated with improved systolic and diastolic function. Interesting, zinc improved some functional variables even in normal rats, similar to the finding of a previous study [8], probably due to a combination of competitive inhibition of calcium influx through the l-type calcium channel, and the modulation of ryanodine receptor-mediated calcium release $[8,10]$.

The beneficial effects of zinc in our study could be explained by different mechanisms, particularly changes in the extracellular matrix, attenuation of oxidative stress, and modulation of inflammatory response [6-16].

The extracellular matrix has a structural role, supporting cardiomyocytes and vessels of the heart and mediating intercellular communication and metabolic changes [29]. The 
main component of the matrix is collagen. The main types of collagen found in cardiac tissue of different species are I and III, which make up 95\% of the total collagen. After infarction, there is high accumulation of collagen (fibrosis) on areas of the myocardium. In this context, fibrosis was associated with increased myocardial stiffness, diastolic dysfunction, weakened contraction, impaired coronary flow, and malignant arrhythmias. In addition, fibrosis was a predictor of mortality in patients with cardiac dysfunction [30, 31]. In our study, zinc supplementation did not decrease the accumulation of collagen induced by the infarction. Thus, we could infer that the decrease in fibrosis was not a mechanism involved in the beneficial effects of zinc in this model.

Another potential mechanism involved in the beneficial effects of zinc is oxidative stress. Strong evidence supports an association between cardiac remodeling and oxidative stress resulting from increased reactive species production or decreased antioxidant defense.

Importantly, oxidative stress would lead to several alterations, such as lipid peroxidation, protein oxidation, DNA damage, cellular dysfunction, proliferation of fibroblasts, induction of apoptosis, changes in calcium-transport proteins, and activation of hypertrophy-signaling pathways $[32,33]$. Consequently, after infarction, cardiac remodeling was attenuatted by administration of different antioxidants products, including tomato/lycopene [34], rosemary [35], probucol [36], green tea [37], and n-acetylcysteine [38].

As expected, in our study, infarction induced several changes in antioxidant enzymes. Importantly, zinc attenuated the infarct-induced changes. Thus, we conclude that the beneficial effects of zinc in this model were mediated, at least in part, by alteration on redox state, but without participation of Nrf-2.

Inflammation is a key modulator of cardiac remodeling. After myocardial infarction, cardiac repair is initiated by intense inflammation and immune cell infiltration, followed by a reparative phase with scar formation. Persistent inflammatory phase participates in the pathogenesis of adverse ventricular remodeling [39]. Recently, it has been accepted that Treg cell plays a prominent role in this process. Treg cells are identified by the expression of CD4+, CD25+, and fork head box P3 (Foxp3) markers and suppress the early inflammatory phase after infarction, contributing to the beginning of the proliferative/reparative phase, associated with IL-10 levels [40]. Therefore, increased Treg cells protected against adverse remodeling following coronary occlusion in rats, via inhibition of inflammation [41]. In contrast, Treg depletion contributed to early postinfarction dilation by increase in the LV end-diastolic volume [42].

An important issue is that the role of Treg cells in the very late phase after myocardial infarction is unknown. In our study, total lymphocytes and Treg cells were increased in the spleen of infarcted animals, associated with IL-10 levels. Likewise, it is accepted that the spleen acts as a reservatory of leucocytes, and their number in the spleen were several folds higher than in circulation early after myocardial infarction [43]. Therefore, our data suggest that Treg cells might be a modulator of deleterious cardiac remodeling in the chronic phase after myocardial infarction in rats, similar to that occurring in the acute phase. However, zinc administration did not change the Treg cells amount and IL-10 levels.

\section{Conclusion}

Zinc supplementation attenuates cardiac remodeling after myocardial infarction in rats; this effect is associated with modulation of antioxidant enzymes, but without the involvement of accumulation of collagens I and III, Nrf-2, IL-10, and Treg cells.

\section{Acknowledgements}

This work was supported by the State of São Paulo Research Foundation (FAPESP: 2013/06862-4 and 2012/14500-2).

\section{KARGER}




\section{Cellular Physiology Cell Physiol Biochem 2018;50:353-362 \begin{tabular}{ll|l} 
and Biochemistry & $\begin{array}{l}\text { DOI: 10.1159/000494011 } \\
\text { Published onlIne: 4 October 2018 }\end{array}$ & $\begin{array}{l}\text { C) } 2018 \text { The Author(s). Published by S. Karger AG, Basel } \\
\text { www.karger.com/cpb }\end{array}$ \\
\hline
\end{tabular}}

Gonçalves et al.: Zinc and Remodeling After Infarction

\section{Disclosure Statement}

The authors declare to have no competing interests.

\section{References}

1 Minicucci MF, Azevedo PS, Polegato BF, Paiva SA, Zornoff LA: Heart failure after myocardial infarction: clinical implications and treatment. Clin Cardiol 2011;34:410-414.

-2 Pfeffer MA, Braunwald E: Ventricular remodeling after myocardial infarction: experimental observations and clinical implications. Circulation 1990;81:1161-1172.

-3 Zornoff LAM, Paiva SAR, Duarte DR, Sparado J: Ventricular remodeling after myocardial infarction: concepts and clinical implications. Arq Bras Cardiol 2009;92:157-164.

$\checkmark 4$ Cohn JN, Ferrari R, Sharpe N: Cardiac remodeling-concepts and clinical implications: a consensus paper from an international forum on cardiac remodeling. J Am Coll Cardiol 2000;35:569-582.

-5 Azevedo PS, Polegato BF, Minicucci MF, Paiva SA, Zornoff LA: Cardiac remodeling: concepts, clinical impact, pathophysiological mechanisms and pharmacologic treatment. Arq Bras Cardiol 2016;106:62-69.

6 Powell SR: The Antioxidant properties of zinc. J Nutr 2000;130: 1447S-1454S.

7 Efeovbokhan N, Bhattacharya SK, Ahokas RA, Sun Y, Guntaka RV, Gerling IC, Weber KT: Zinc and the prooxidant heart failure phenotype. J Cardiovasc Pharmacol 2014;64:393-400.

8 Yi T, Vick JF, Vecchio MF, Begin KF, Bell SF, Delay RF, Palmer BM: Identifying cellular mechanisms of zincinduced relaxation in isolated cardiomyocytes. Am J Physiol Heart Circ Physiol 2013;305:H706-H715.

-9 Tuncay E, Bilginoglu A, Sozmen NN, Zeydanli EN, Ugur M, Vassort G, Turan B: Intracellular free zinc during cardiac excitation-contraction cycle: calcium and redox dependencies. Cardiovasc Res 2011;89:634-642.

10 Woodier J, Rainbow R D, Stewart AJ, Pitt SJ: Intracellular zinc modulates cardiac ryanodine receptormediated calcium release. J Biol Chem 2015;290:17599-17610.

11 Bodiga VL, Thokala S, Kovur SM, Bodiga S: Zinc dyshomeostasis in cardiomyocytes after acute hypoxia/ reoxygenation. Biol Trace Elem Res 2017;179:117-129.

-12 Little PJ, Bhattacharya R, Moreyra AE, Korichneva IL: Zinc and cardiovascular disease. Nutrition 2010;26:1050-1057.

13 Yi T, Cheema YF, Tremble SM, Bell SP, Chen ZF, Subramanian MF, LeWinter MM, VanBuren P, Palmer BM: Zinc-induced cardiomyocyte relaxation in a rat model of hyperglycemia is independent of myosin isoform. Cardiovasc Diabetol 2012;11:1475-2840.

-14 Woodier J, Rainbow RD, Stewart AJ, Pitt SJ: Intracellular zinc modulates cardiac ryanodine receptormediated calcium release. J Biol Chem 2015;290:17599-17610.

15 Alexanian I, Parissis J, Farmakis D, Athanaselis S, Pappas L, Gavrielatos G, Mihas C, Paraskevaidis I, Sideris A, Kremastinos D, Spiliopoulou C, Anastasiou-Nana M, Lekakis J, Filippatos G: Clinical and echocardiographic correlates of serum copper and zinc in acute and chronic heart failure. Clin Res Cardiol 2014;103:938-949.

16 McKeag NA, McKinley MC, Woodside JV, Harbinson MT, McKeown PP: The role of micronutrients in heart failure. Acad Nutr Diet 2012;112:870-886.

17 Pfeffer JM, Finn PV, Zornoff LA, Pfeffer MA: Endothelin-A receptor antagonism during acute myocardial infarction in rats. Cardiovasc Drugs Ther 2000;14:579-587.

$>18$ Paiva SA, Novo R, Matsubara BB, Matsubara LS, Azevedo PS, Minicucci MF, Campana AO, Zornoff LA: $\beta$-carotene attenuates the paradoxical effect of tobacco smoke on the mortality of rats after experimental myocardial infarction. J Nutr 2005;135:2109-2113.

19 Minicucci MF, Azevedo PS, Martinez PF, Lima AR, Bonomo C, Guizoni DM, Polegato BF, Okoshi MP, Okoshi K, Matsubara BB, Paiva SA, Zornoff LA: Critical infarct size to induce ventricular remodeling, cardiac dysfunction and heart failure in rats. Int J Cardiol 2011;151:242-243.

20 Wang J, Song Y, Elsherif L, Song Z, Zhou G, Prabhu SD, Saari JT, Cai L: Cardiac metallothionein induction plays the major role in the prevention of diabetic cardiomyopathy by zinc supplementation. Circulation 2006;113:544-554. 


\section{Cellular Physiology Cell Physiol Biochem 2018;50:353-362 \begin{tabular}{ll|l} 
and Biochemistry Published online: 4 October 2018 & $\begin{array}{l}\text { C } 2018 \text { The Author(s). Published by S. Karger AG, Basel } \\
\text { www.karger.com/cpb }\end{array}$ \\
\hline
\end{tabular}}

-21 Martinez PF, Okoshi K, Zornoff LA, Oliveira SA Jr, Campos DH, Lima AR, Damatto RL, Cezar MD, Bonomo C, Guizoni DM, Padovani CR, Cicogna AC, Okoshi MP: Echocardiographic detection of congestive heart failure in postinfarction rats. J Appl Physiol 2011;111:543-551.

-22 Minicucci MF, Azevedo PS, Oliveira SA Jr, Martinez PF, Chiuso-Minicucci F, Polegato BF, Justulin LA Jr, Matsubara LS, Matsubara BB, Paiva SA, Zornoff LA: Tissue vitamin A insufficiency results in adverse ventricular remodeling after experimental myocardial infarction. Cell Physiol Biochem 2010;26:523-530.

23 Azevedo PS, Minicucci MF, Chiuso-Minicucci F, Justulin Jr LA, Matsubara LS, Matsubara BB, Novelli E, Seiva F, Ebaid G, Campana AO, Zornoff LA, Paiva SA: Ventricular remodeling induced by tissue vitamin A deficiency in rats. Cell Physiol Biochem 2010;26:395-402.

-24 Zornoff LA, Paiva SA, Minicucci MF, Spadaro J: Experimental myocardium infarction in rats: analysis of the model. Arq Bras Cardiol 2009;93:434-440.

25 Assalin HB, Rafacho BP, dos Santos PP, Ardisson LP, Roscani MG, Chiuso-Minicucci F, Barbisan LF, Fernandes AA, Azevedo PS, Minicucci MF, Zornoff LA, de Paiva SA: Impact of the length of vitamin D deficiency on cardiac remodeling. Circ Heart Fail 2013;6:809-816.

26 Silva RAC, Gonçalves AF, Dos Santos PP, Rafacho B, Claro RFT, Minicucci MF, Azevedo PS, Polegato BF, Zanati SG, Fernandes AA, Paiva SAR, Zornoff LAM: Cardiac remodeling induced by all-trans retinoic acid is detrimental in normal rats. Cell Physiol Biochem 2017;43:1449-1459.

27 Maret W: Zinc and human disease. Met Ions Life Sci. 2013;13:389-414.

-28 Korkmaz S, Atmanli A, Li S, Radovits T, Hegedüs P, Barnucz E, Hirschberg K, Loganathan S, Yoshikawa Y, Yasui H, Karck M, Szabó G: Superiority of zinc complex of acetylsalicylic acid to acetylsalicylic acid in preventing postischemic myocardial dysfunction. Exp Biol Med 2015;240:1247-1255.

29 Li A-H, Liu PP, Villarreal FJ, Garcia RA: Dynamic changes in myocardial matrix and relevance to disease: translational perspectives. Circ Res 2014;114:916-927.

-30 López B, González A, Ravassa S, Beaumont J, Moreno MU, San José G, Querejeta R, Díez J: Circulating biomarkers of myocardial fibrosis: the need for a reappraisal. J Am Coll Cardiol 2015;65:2449-2456.

31 Leask A: Getting to the heart of the matter: new insights into cardiac fibrosis. Circ Res 2015;116:12691276.

-32 Sawyer DB, Siwik DA, Xiao L, Pimentel DR, Singh K, Colucci WS: Role of oxidative stress in myocardial hypertrophy and failure. J Mol Cell Cardiol 2002;34:379-388.

-33 Munzel T, Gori T, Keaney JF Jr, Maack C, Daiber A: Pathophysiological role of oxidative stress in systolic and diastolic heart failure and its therapeutic implications. Eur Heart J 2015;36:2555-2564.

-34 Pereira BLB, Reis PP, Severino FE, Felix TF, Braz MG, Nogueira FR, Silva RAC, Cardoso AC, Lourenço MAM, Figueiredo AM, Chiuso-Minicucci F, Azevedo PS, Polegato BF, Okoshi K, Fernandes AAH, Paiva SAR, Zornoff LAM, Minicucci MF: Tomato (Lycopersicon esculentum) or lycopene supplementation attenuates ventricular remodeling after myocardial infarction through different mechanistic pathways. J Nutr Biochem 2017;46:117-124.

-35 Rafacho BP, Santos PP, Gonçalves AF, Fernandes AAH, Okoshi K, Chiuso-Minicucci F, Azevedo PS, Zornoff LA, Minicucci MF, Wang XD, Paiva SA: Rosemary supplementation (Rosmarinus oficinallis L.) attenuates cardiac remodeling after myocardial infarction in rats. PLoS One 2017;12:e0177521.

-36 Zhou SX, Zhou Y, Zhang YL, Lei J, Wang JF: Antioxidant probucol attenuates myocardial oxidative stress and collagen expressions in post-myocardial infarction rats. J Cardiovasc Pharmacol 2009;54:154-162.

-37 Lustosa BB, Polegato B, Minicucci M, Rafacho B, Santos PP, Fernandes AA, Okoshi K, Batista D, Modesto P, Gonçalves A, Pereira EJ, Pires V, Paiva SA, Zornoff L, Azevedo PS: Green tea (Cammellia sinensis) attenuates ventricular remodeling after experimental myocardial infarction. Int J Cardiol 2016;225:147-153.

38 Martinez PF, Bonomo C, Guizoni DM, Junior SA, Damatto RL, Cezar MD, Lima AR, Pagan LU, Seiva FR, Fernandes DC, Laurindo FR, Novelli EL, Matsubara LS, Zornoff LA, Okoshi K, Okoshi MP: Influence of Nacetylcysteine on oxidative stress in slow-twitch soleus muscle of heart failure rats. Cell Physiol Biochem 2015;35:148-159.

39 Prabhu SD, Frangogiannis NG: The Biological basis for cardiac repair after myocardial infarction: from inflammation to fibrosis. Circ Res 2016;119:91-112.

40 Wang YP, Xie Y, Ma H, Su SA, Wang YD, Wang JA, Xiang MX: Regulatory T lymphocytes in myocardial infarction: A promising new therapeutic target. Int J Cardiol 2016;203:923-928. 


\section{Cellular Physiology Cell Physiol Biochem 2018;50:353-362 \begin{tabular}{l|l} 
DOI: 10.1159/000494011 & $\begin{array}{l}\text { O 2018 The Author(s). Published by S. Karger AG, Basel } \\
\text { www.karger.com/cpb }\end{array}$ \\
\hline
\end{tabular} \\ Gonçalves et al.: Zinc and Remodeling After Infarction}

41 Tang TT, Yuan J, Zhu ZF, Zhang WC, Xiao H, Xia N, Yan XX, Nie SF, Liu J, Zhou SF, Li JJ, Yao R, Liao MY, Tu X, Liao YH, Cheng X: Regulatory T cells ameliorate cardiac remodeling after myocardial infarction. Basic Res Cardiol 2012;107:232.

42 Saxena A, Dobaczewski M, Rai V, Haque Z, Chen W, Li N, Frangogiannis NG: Regulatory T cells are recruited in the infarcted mouse myocardium and may modulate fibroblast phenotype and function. Am J Physiol Heart Circ Physiol 2014;307: H1233-H1242.

-43 Kain V, Prabhu SD, Halade GV: Inflammation revisited: inflammation versus resolution of inflammation following myocardial infarction. Basic Res Cardiol 2014;109:444. 